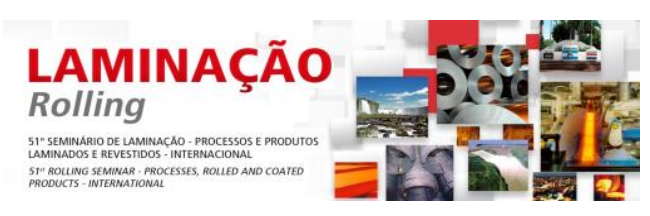

\title{
CARACTERIZAÇÃO E ESTAMPABILIDADE DE UM AÇO SAE 1080 FOSFATIZADO*
}

Daniel Augusto Ferro ${ }^{1}$

Ronald Lesley Plaut ${ }^{2}$

\section{Resumo}

Devido crescente necessidade de elevação dos níveis de conformação em peças estampadas, existe uma demanda cada vez maior em ligas e processos diversificados que atendam as variadas exigências do setor de produtos estampados e posteriormente tratados termicamente para aumento de dureza. Desse modo desenvolveu-se a liga C80M (modificada), que é uma variante da liga C80U especificada na norma DIN EN ISO 4957 porém com adição de Cromo, entretanto a liga C80M ainda é pouco estudada e pouca informação técnica se tem a seu respeito. Com a finalidade de melhor conhecimento técnico dessa liga, foram conduzidos estudos de caracterização em amostras laminadas a quente e após processo de esferoidização posteriormente sendo revestidas com fosfato de zinco. Foram realizados estudos de composição química, microestrutura e propriedades mecânicas, além de levantamento da curva CLC através do método Nakazima em amostras com e sem revestimento de fosfato. Através dos resultados parciais encontrados, foi possível definir o lado da curva CLC relacionado ao estiramento da chapa bem como comparar o deslocamento e a força do punção no teste Nakazima conformando-se amostras esferoidizadas sem e com revestimento de fosfato.

Palavras-chave: C80M; Ensaio Nakazima; Fosfato de zinco; Curva limite de conformação.

\section{CHARACTERIZATION AND STAMPABILITY OF A PHOSPHATIZED STEEL SAE 1080}

\section{Abstract}

According to the necessity of higher forming levels in general for stamping parts, there is a higher demand in alloys and diversified process that meet the variety requirements of the stamped products and that are subsequently heat treated to increase hardness. Thus the alloy C80M has been developed, which is a variant of alloy C80U specified in the standard DIN EN ISO 4957 but with addition of Chrome, however this alloy is still poorly studied and few technical information available about it. In order to increase the knowledge of this alloy, characterization studies were conducted on hot rolled, after spheroidization and subsequently coated with zinc phosphate samples. The studies realized included chemical composition, microstructure and mechanical properties, as well as Nakazima tests in order to obtain the forming limit diagram (FLD) curve in spheroidized samples coated and uncoated after the stamping process. Through the partial results, it was possible to define the side of FLD curve related to stretching of the plate as well as comparing the displacement and force of the punch on Nakazima test, stamping spheroidized samples both uncoated and coated with zinc phosphate.

Keywords: C80M; Nakazima test; Zinc phosphate; Forming limit diagram.

1 Engenheiro Mecânico, Engenheiro de Desenvolvimento de Produto da Brasmetal Waelzholz S/A, Diadema, SP, Brasil; dferro@brasmetal.com.br.

2 Ph.D. em Metalurgia, Professor Associado (aposent.), São Paulo, SP, Brasil.

\footnotetext{
* Contribuição técnica ao $51^{\circ}$ Seminário de Laminação - Processos e Produtos Laminados e Revestidos, 28 a 31 de outubro de 2014, Foz do Iguaçu, PR, Brasil.
} 


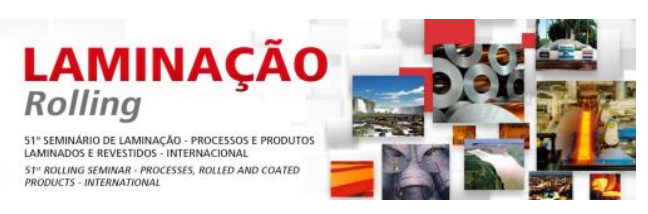

\section{INTRODUÇÃO}

Existe uma variada gama de processos e materiais para a confecção de anéis internos e externos de rolamentos. Entre eles pode-se destacar o processo de estampagem a partir de aço baixo carbono com posterior tratamento térmico de cementação seguida de têmpera, entretanto tal processo eleva o custo da peça final devido à obrigatoriedade em se obter uma camada mínima de difusão gerando maior tempo de forno. Devido ao elevado grau de conformação e necessidade de posterior processo de tratamento térmico de endurecimento, seja ele cementação, têmpera seguida de revenimento ou austêmpera, os anéis internos e externos do rolamento, quando estampados a partir de aços de maior temperabilidade, devem apresentar alta porcentagem de esferoidização bem como baixíssimos níveis de inclusões, de modo a viabilizar o processo de estampagem com têmpera direta seguida de revenimento, ou mesmo austêmpera para produção destes componentes a um custo menor [1].

Tradicionalmente o aço utilizado na estampagem de rolamentos para têmpera plena é o 100Cr6 ou seu equivalente SAE 52100, entretanto devido à elevada concentração de elementos de liga, principalmente o carbono, sua resistência mecânica também se torna elevada o que dificulta o processo de estampagem a frio, sendo necessário o desenvolvimento de um aço com menor concentração de elementos de liga e menores propriedades mecânicas, mantendo a temperabilidade para que após os processos de conformação, têmpera e revenimento, a peça atenda as características necessárias para aplicação em rolamentos como elevada resistência mecânica e ao desgaste além de estabilidade dimensional após têmpera. Neste contexto foi desenvolvido o aço C80M (modificado), que corresponde a uma variante do aço C80U conforme DIN EN ISO 4957. Na tabela 1 é possível comparar as composições químicas dos aços 100Cr6, C80U e C80M [1].

Tabela 1: Composição química (\% em peso) dos aços 100Cr6, C80U e C80U Mod. (extraído de Martins, 2012).

\begin{tabular}{|ccccccccc}
\hline & & $\mathbf{C}$ & $\mathbf{S i}$ & $\mathbf{M n}$ & $\mathbf{P}$ & $\mathbf{S}$ & $\mathbf{C r}$ & $\mathbf{A l}$ \\
DIN 100Cr6 & $\min$. & 0,93 & 0,15 & 0,25 & & & 1,35 & \\
& $\max$. & 1,05 & 0,35 & 0,45 & 0,025 & 0,015 & 1,60 & 0,050 \\
DIN C80U & $\min$. & 0,75 & 0,10 & 0,10 & & & -- & --- \\
& $\max$. & 0,85 & 0,30 & 0,40 & 0,030 & 0,030 & --30 & \\
C80U Mod. & $\min$. & 0,70 & & 0,10 & & & 0,30 & -- \\
\hline & $\max$. & 0.85 & 0,35 & 0,80 & 0,030 & 0,015 & 0,70 & \\
\hline
\end{tabular}

No auxílio do processo de estampagem uma das frentes de trabalho é a redução no coeficiente de atrito, possível devido à utilização de óleos lubrificantes que podem atuar isoladamente ou em conjunto com revestimentos. Entre os revestimentos que atuam em conjunto com o óleo pode-se destacar o fosfato que evita contato $\mathrm{metal} / \mathrm{metal}$ além de reter lubrificante auxiliando no processo de estampagem [2].

Com base no exposto, os principais objetivos do trabalho são efetuar a caracterização química e metalográfica do aço C80M laminado a quente e eferoidizado além de avaliar sua conformabilidade através de ensaios básicos (ensaio Erichsen/Nakazima) visando obter as curvas limite de conformação para as condições sem e com camada de fosfato de zinco (mais sabão).

\footnotetext{
* Contribuição técnica ao $51^{\circ}$ Seminário de Laminação - Processos e Produtos Laminados e Revestidos, 28 a 31 de outubro de 2014, Foz do Iguaçu, PR, Brasil.
} 


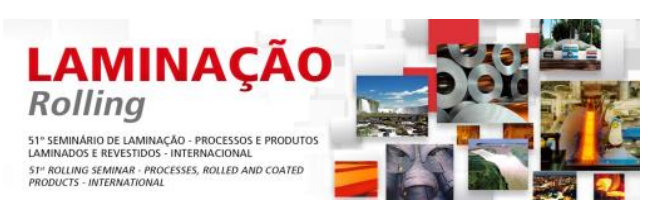

\subsection{Ensaio Nakazima}

De acordo com Nakazima [3] este ensaio reproduz, com um único ferramental, os estados de deformação uniaxial e biaxial, através da deformação imposta por um punção semi-esférico em chapas metálicas retangulares que variam de largura e são fixas por uma matriz e um prensa-chapas. O ferramental encontra-se exemplificado na figura 1:

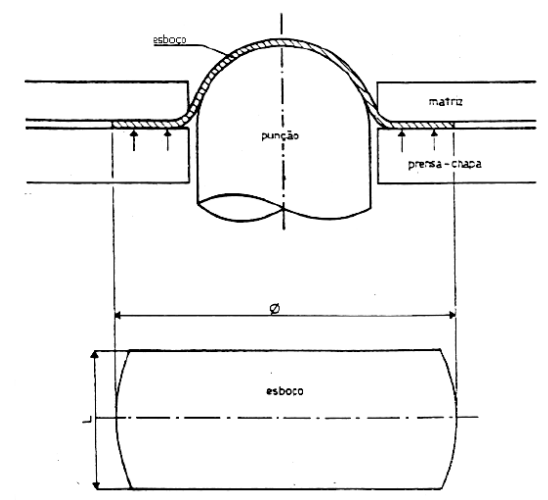

Figura 1: Ferramental do ensaio Nakazima [3].

\subsection{Curva Limite De Conformação "CLC"}

Segundo Reyman [4], a CLC ou FLD "Forming Limit Diagram" é uma curva empírica construída com o intuito de descrever os estados de deformação ou combinações entre a maior $\left(\varepsilon_{1}\right)$ e menor $\left(\varepsilon_{2}\right)$ deformações principais, onde uma localizada zona de afinamento ou formação de pescoço se torna visível na superfície da tira metálica. A curva deriva de dados laboratoriais levantados a partir de experimentos realizados em uma prensa de 1963 a 1965 [5].

De acordo com Keeler [6], Goodwin [7], Holmberg [8] e Marciniak [9], a CLC mostra a quantidade de deformação que uma tira pode resistir em função do modo de deformação sendo uma relação entre a maior e menor deformação aplicada à tira conforme figura 2 :

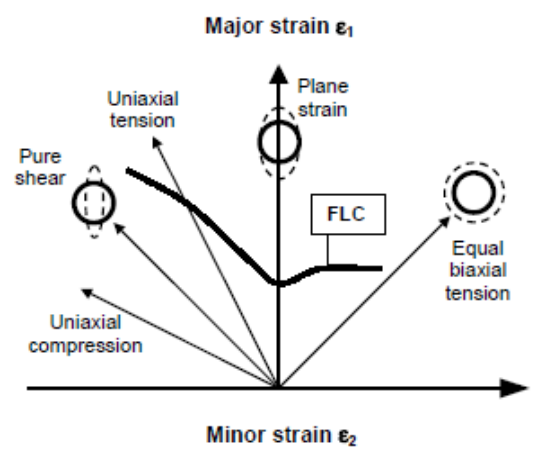

Figura 2: Curva limite de conformação ou forming limit curve [8].

Na figura 2 são indicados os principais modos de deformação, o ponto mínimo da curva é normalmente o ponto associado com a deformação planar.

De modo a evitar fraturas, é importante que os níveis de deformação, em qualquer ponto da peça estampada, sejam sempre inferiores ao delimitado pela curva onde é usual se definir uma margem de segurança resultando em um deslocamento da

* Contribuição técnica ao $51^{\circ}$ Seminário de Laminação - Processos e Produtos Laminados e Revestidos, 28 a 31 de outubro de 2014, Foz do Iguaçu, PR, Brasil. 


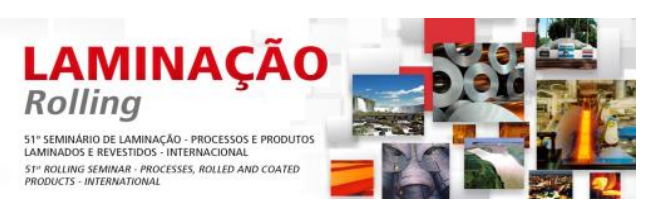

CLC. O risco de fratura é determinado medindo-se as deformações da peça e verificando-se quão próximas estão da CLC.

\subsection{Aplicações das Camadas Fosfatizadas}

Camadas de fosfato são usadas para uma variedade de aplicações, entre elas destacam-se: proteção contra corrosão, como base de pintura, aumento da resistência ao desgaste e como auxílio para deformação a frio dos aços [10].

A camada fosfatizada por si só não tem poder lubrificante, a lubrificação das camadas fosfatizadas advém da propriedade de retenção de óleos lubrificantes e sabão. A diminuição do desgaste de peças fosfatizadas também se dá devido à formação de barreiras não metálicas que separam a duas superfícies metálicas em contato e reduzem o risco de ataque e corrosão associados.

Uma combinação entre fosfato de zinco e um filme lubrificante previne arranhões na superfície do metal em operações de estampagem e diminui substancialmente a quantidade de produtos defeituosos [10].

De acordo com Narayanan [11], as camadas fosfatizadas utilizadas com o intuito de auxiliar na conformação apresentam as seguintes características:

- Atuam como redutores de atrito;

- Aumentam a velocidade em operações de conformação;

- Reduzem consumo de energia;

- Aumentam a vida da ferramenta e dos punções.

\subsection{Recozimento de Esferoidização}

A esferoidização é um processo de ajuste morfológico que se dá sob a ação da energia superficial, onde ocorre uma evolução microestrutural da perlita pelo mecanismo de coalecimento, com consequente formação de carbonetos globulares em uma matriz ferrítica. Partículas de cementita lamelar, presentes na perlita, têm uma área de superfície por unidade de volume de partícula muito grande, e, portanto, uma elevada energia interfacial. A fim de reduzir esta energia, as lamelas de cementita ou placas se quebram em pequenas partículas que eventualmente assumem forma esférica. Uma vez quebrada as lamelas, as menores partículas esféricas se dissolvem à custa do crescimento das maiores, novamente em função da redução da energia interfacial.

Quanto maior é o grau de esferoidização, menores serão as propriedades mecânicas (limites de resistência e escoamento) e maiores serão os valores de alongamento [12].

De acordo com Storojeva et. al. [13], a morfologia globular da cementita traz alguns benefícios como alta tenacidade, boa conformação a frio e usinabilidade. Em alguns casos a tira laminada a frio deve passar por longos processos de recozimento garantindo elevado grau de esferoidização para se obter altas taxas de deformação a frio.

\section{MATERIAIS E MÉTODOS}

Partindo-se de uma material C80M laminado a quente e posteriormente relaminado e esferoidizado sem e com revestimento de fosfato de zinco e sem tratamento térmico de endurecimento coletaram-se amostras para análise de conformação

\footnotetext{
* Contribuição técnica ao $51^{\circ}$ Seminário de Laminação - Processos e Produtos Laminados e Revestidos, 28 a 31 de outubro de 2014, Foz do Iguaçu, PR, Brasil.
} 


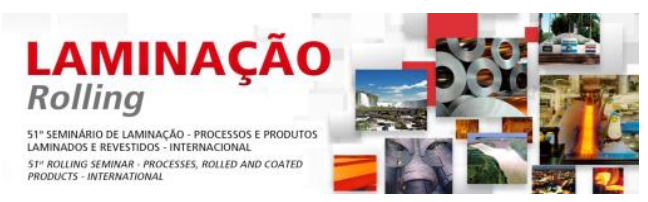

(ensaio Nakazima) sem lubrificante adicional, bem como caracterização química, microestrutural e mecânica.

\subsection{Processo de Relaminação}

A figura 3 se faz necessária para melhor entendimento da sequência de processo de relaminação onde está destacado pelas setas em vermelho a sequência de processos do material estudado, partindo-se bobina laminada a quente de dimensões 2,65 $\times 450 \mathrm{~mm}$, e pelas setas em verde os pontos de coleta das amostras analisadas (amostra laminada a quente - espessura de 2,65mm e após processo de relaminação e esferoidização - espessura de 1,50mm).

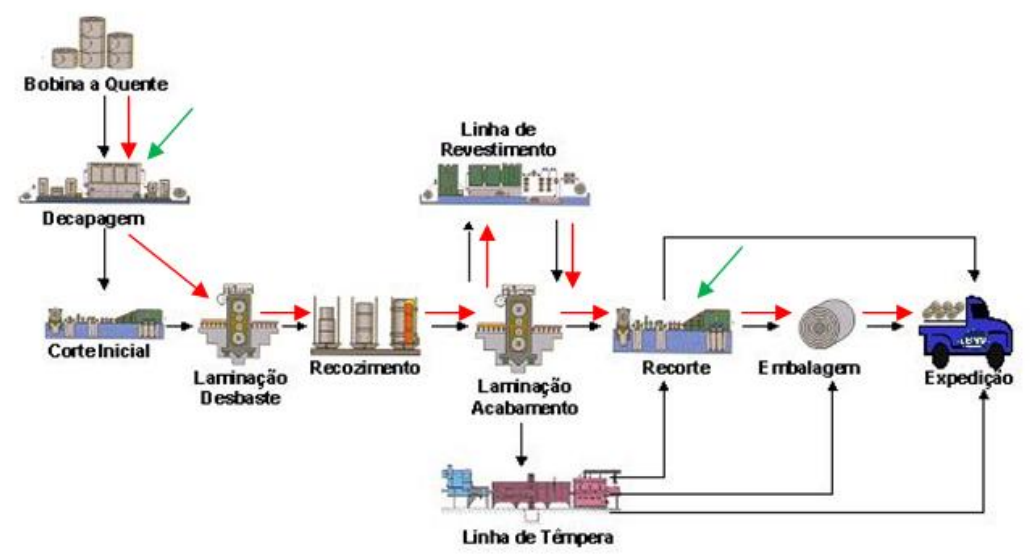

Figura 3: Fluxo de processo de laminação a frio e indicação de pontos de coleta de amostras.

\subsection{Composição Química}

A análise de composição química foi realizada em amostra no estado laminado à quente em espectrofotômetro de emissão óptica do fabricante Spectrolab.

\subsection{Propriedades Mecânicas e Anisotropia}

As propriedades mecânicas e anisotropia plástica foram obtidas conforme normas NBR 6673:1981 e ASTM E517:2010 respectivamente, foram retirados três corpos de prova do material no estado relaminado e recozido (paralelo, a $45^{\circ}$ e a $90^{\circ}$ do sentido de laminação) com posterior laminação de encruamento "skin pass". As dimensões do corpo de prova de tração são mostradas na figura 4

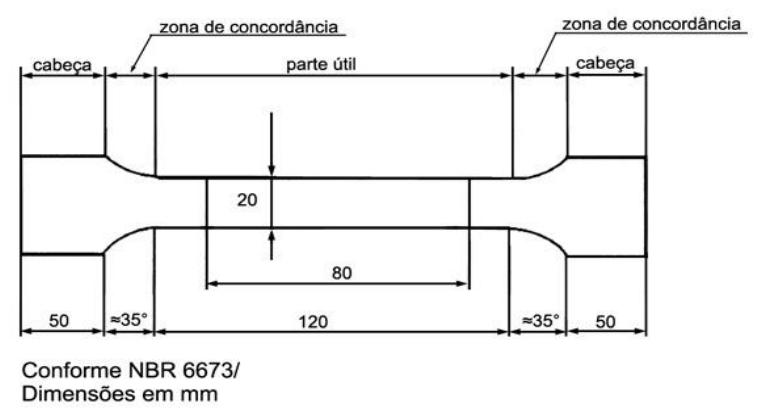

Figura 4: Geometria do corpo de prova para ensaio de tração (NBR 6673: 1981)

Os ensaios foram realizados em máquina de tração Zwick modelo Z250 equipada com garras hidráulicas e extensômetros.

* Contribuição técnica ao $51^{\circ}$ Seminário de Laminação - Processos e Produtos Laminados e Revestidos, 28 a 31 de outubro de 2014, Foz do Iguaçu, PR, Brasil. 


\section{$\underset{\text { Lolling }}{\text { LANIÇÃO }}$

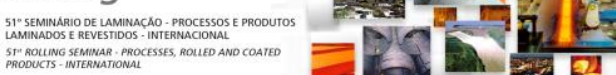

Os valores do coeficiente de encruamento foram determinados para deformações entre $8 \%$ e $12 \%$ também conhecida como alongamento de deformação uniforme.

\subsection{MICROESTRUTURA E NÍVEL DE INCLUSÕES}

Para análise da microestrutura e nível de inclusões, uma amostra laminada a quente e outra após processo de laminação a frio foram retiradas e devidamente polidas para visualização da estrutura no sentido de laminação conforme ilustra a figura 5

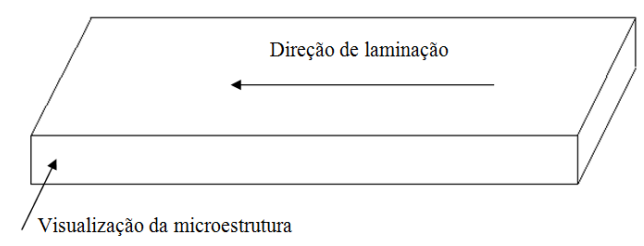

Figura 5: llustração da amostragem para avaliação do nível de inclusões

\subsection{Ensaio Nakazima}

Para os testes de conformação pelo método Nakazima foram retiradas seis amostras do mesmo lote (C80M esferoidizado) de cada uma das larguras conforme figura 6.
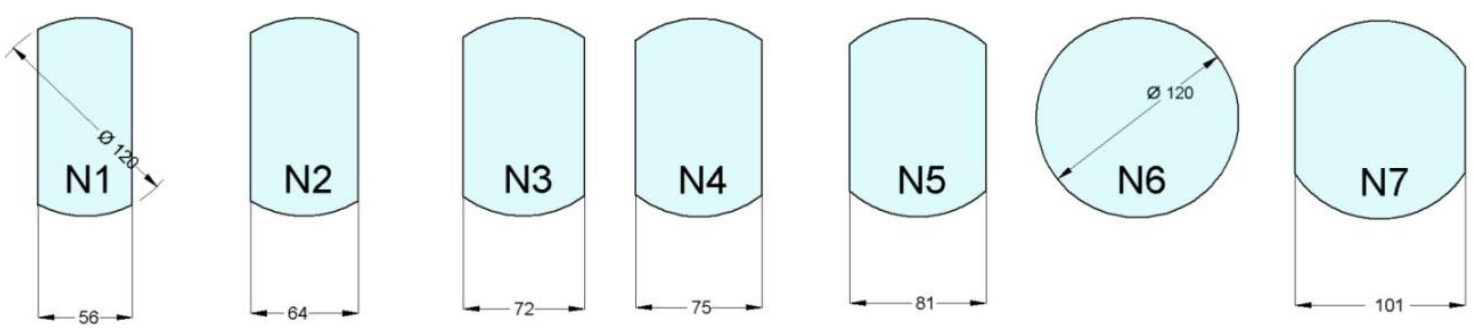

Figura 6: Dimensões das amostras conformadas pelo método Nakazima

Com o auxílio de gravador eletroquímico da marca Tecnigrav modelo RB-200 e tela com malha, foram gravados círculos de diâmetro de $2 \mathrm{~mm}$ na superfície externa do domo, em todas as amostras antes da conformação. A figura 7 mostra o gravador eletroquímico bem como a amostra com a malha já gravada.
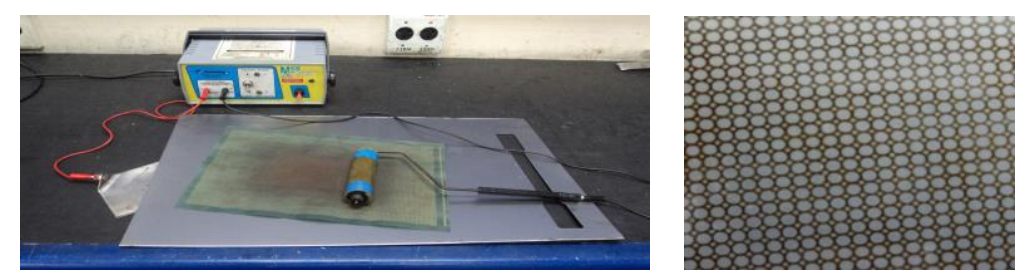

Figura 7: Gravador eletroquímico e amostra gravada para análise das deformações principais após conformação pelo método Nakazima.

Seis amostras de cada largura foram conformadas, três com a presença do fosfato de zinco mais sabão e três amostras sem revestimento. Todas as amostras foram conformadas sem utilização de óleo lubrificante.

* Contribuição técnica ao $51^{\circ}$ Seminário de Laminação - Processos e Produtos Laminados e Revestidos, 28 a 31 de outubro de 2014, Foz do Iguaçu, PR, Brasil. 


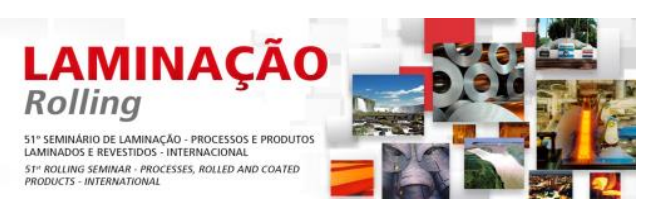

A conformação das amostras foi feita em equipamento da marca Erichsen, modelo 142-20 conforme figura 8, com controle de força do prensa chapa e velocidade do punção. Este equipamento também tem sensores que indicam o curso e força no punção. As conformações foram feitas com velocidade do punção de $10 \mathrm{~mm} / \mathrm{minuto}$, força do prensa chapas de 40 kN e diâmetro do punção de $50 \mathrm{~mm}$.

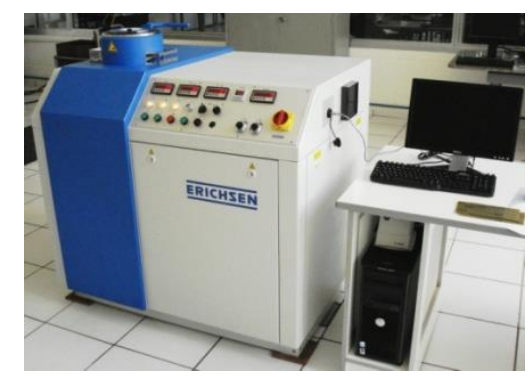

Figura 8: Equipamento Erichsen para conformação pelo método Nakazima

Foram medidos altura e força máxima do punção, que foi parado através de acionamento manual após de afinamento de parede localizado (avaliação visual).

As imagens capturadas da superfície das amostras foram processadas no software AutoCAD ${ }^{\circ}$ para medição das deformações da malha previamente gravada. Os círculos adjacentes à região de deformação localizada foram avaliados conforme indicado na figura 9 [14]. Para a medição dos diâmetros principais da malha gravada nos corpos de prova sem a perda de referência e escala, foi realizada a captura da imagem com um dispositivo, composto por uma câmera fotográfica digital, haste magnética, desempeno em aço e escala de medição, conforme pode ser visto na figura 9.
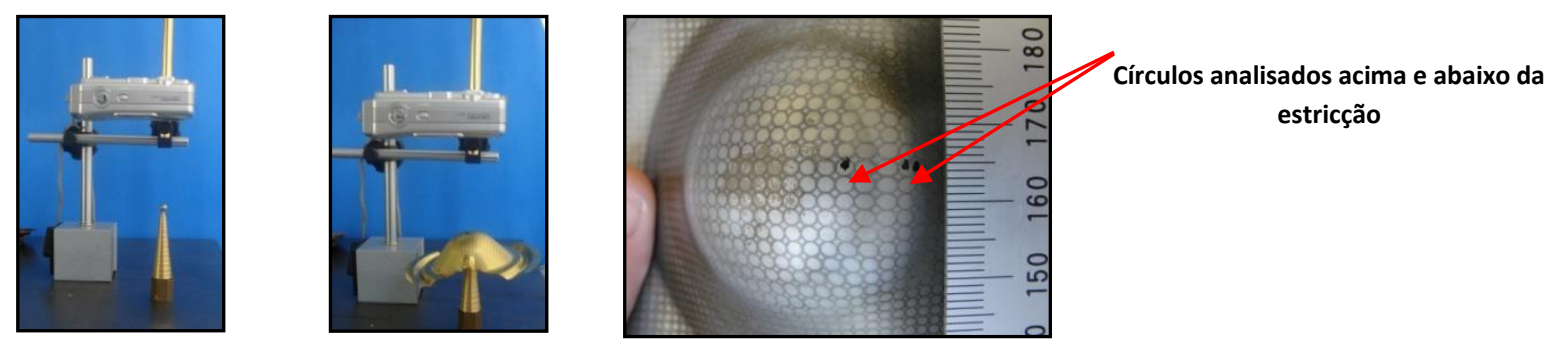

Figura 9: Dispositivo para captura dos diâmetros principais e detalhe da imagem capturada

O comprimento (W) e largura $(\mathrm{H})$ medidos nos círculos deformados após a conformação dos corpos de prova foram tomados de acordo com a figura 10 .

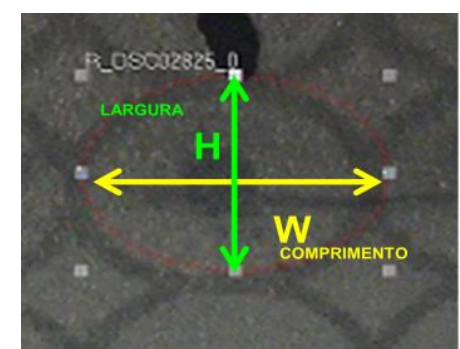

Figura 10: Tomada dos diâmetros principais

Para cada corpo de prova conformado foram medidos os valores dos diâmetros principais ( $\mathrm{H}$ e W) nas elipses acima e abaixo do ponto de trinca e/ou estricção.

* Contribuição técnica ao $51^{\circ}$ Seminário de Laminação - Processos e Produtos Laminados e Revestidos, 28 a 31 de outubro de 2014, Foz do Iguaçu, PR, Brasil. 


\section{LAMINAÇÃO \\ Rolling}

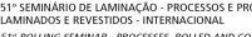

Foram utilizados os valores dos diâmetros principais encontrados para o cálculo das deformações principais $\varepsilon_{1} \mathrm{e}^{\varepsilon_{2}}$, para tal usou-se as equações 1 e 2 .

$$
\begin{aligned}
& \varepsilon_{1}=L n *\left(\frac{W}{2}\right) ; \\
& 1 \\
& \varepsilon_{2}=L n *\left(\frac{H}{2}\right) .
\end{aligned}
$$

2

Após calculados os valores das deformações principais, os mesmos foram plotados em um gráfico com eixo das abcissas $\varepsilon_{2}$ e eixo da ordenadas ${ }^{\varepsilon_{1}}$, obtendo-se dessa forma a curva CLC do material C80M esferoidizado.

\section{RESULTADOS}

\subsection{Composição Química}

Os resultados de composição química encontram-se na tabela 2:

Tabela 2: Resultados de composição química

\begin{tabular}{|c|c|c|c|c|c|c|}
\cline { 2 - 7 } \multicolumn{1}{c|}{} & $\mathrm{C}$ & $\mathrm{Si}$ & $\mathrm{Mn}$ & $\mathrm{P}$ & $\mathrm{S}$ & $\mathrm{Cr}$ \\
\hline C80M & 0,77 & 0,134 & 0,34 & 0,011 & 0,0014 & 0,42 \\
\hline
\end{tabular}

\subsection{Propriedades Mecânicas e Anisotropia}

Ensaio de tração realizado em amostra do material relaminado e esferoidizado apresentaram os resultados conforme destacado na tabela 3 :

\begin{tabular}{|c|c|c|c|c|c|c|c|c|c|c|c|c|c|c|c|c|c|c|}
\hline $\mathrm{Nr}$ & $\begin{array}{c}\text { Esp. } \\
\mathrm{mm}\end{array}$ & Nr.rolo & |Int//Ext/Meio & Posição & $\begin{array}{l}\text { L.R. } \\
\mathrm{N} / \mathrm{mm}^{2}\end{array}$ & $\underset{\mathrm{N} / \mathrm{mm}^{2}}{\mathrm{LE}}$ & $\mathrm{RE}$ & $\begin{array}{c}\mathrm{Al}(80) \\
\%\end{array}$ & $\begin{array}{c}A_{5,65} \\
\%\end{array}$ & $\begin{array}{c}\mathrm{A}_{11,3} \\
\%\end{array}$ & r-value & $\mathrm{rm}$ & r & $\mathrm{dr}$ & $\mathrm{n}$ & $\mathrm{nm}$ & $\begin{array}{l}\text { E-Mod. } \\
\mathrm{N} / \mathrm{mm}^{2}\end{array}$ & $\begin{array}{c}\mathrm{K} \\
\mathrm{N} / \mathrm{mm}^{2}\end{array}$ \\
\hline 1 & 1,486 & 1 & Ext. & $0^{\circ}$ & 527,13 & 402,45 & 0,76 & 25,90 & 38,06 & 28,84 & 0,85 & 0,99 & 0,85 & 0,11 & 0,129 & 0,13 & 186392,4 & 781,48 \\
\hline & & & & & & & & & & & \begin{tabular}{|l|}
0,85 \\
0,86 \\
\end{tabular} & & & & & & & \\
\hline 2 & 1,482 & 1 & Ext. & $45^{\circ}$ & 530,91 & 413,32 & 0,78 & 25,11 & 36,93 & 27,99 & $\begin{array}{l}0,92 \\
0,93 \\
0,94\end{array}$ & & 0,93 & & 0,128 & & \begin{tabular}{|l|}
190349,3 \\
\end{tabular} & 784,55 \\
\hline 3 & 1,486 & 1 & Ext. & $90^{\circ}$ & 533,65 & 412,28 & 0,77 & 24,49 & 35,99 & 27,27 & $\begin{array}{l}1,24 \\
1,23 \\
1,23\end{array}$ & & 1,23 & & 0,130 & & 204134,1 & 792,60 \\
\hline
\end{tabular}

Tabela 3: Propriedades mecânicas no sentido de laminação, a 45 graus do sentido de laminação a 90 graus do sentido de laminação.

\subsection{Microestrutura Óptica (MO)}

Na figura 11 é possível verificar a microestrutura do material laminado a quente (a) e após processo de esferoidização (b). Conforme DIN SEP 1520:1998 constatou-se nível de esferoidização de $100 \%$ através de análise comparativa. Para esta análise foi utilizado o reagente nital em uma concentração de $3 \%$ :

* Contribuição técnica ao $51^{\circ}$ Seminário de Laminação - Processos e Produtos Laminados e Revestidos, 28 a 31 de outubro de 2014, Foz do Iguaçu, PR, Brasil. 

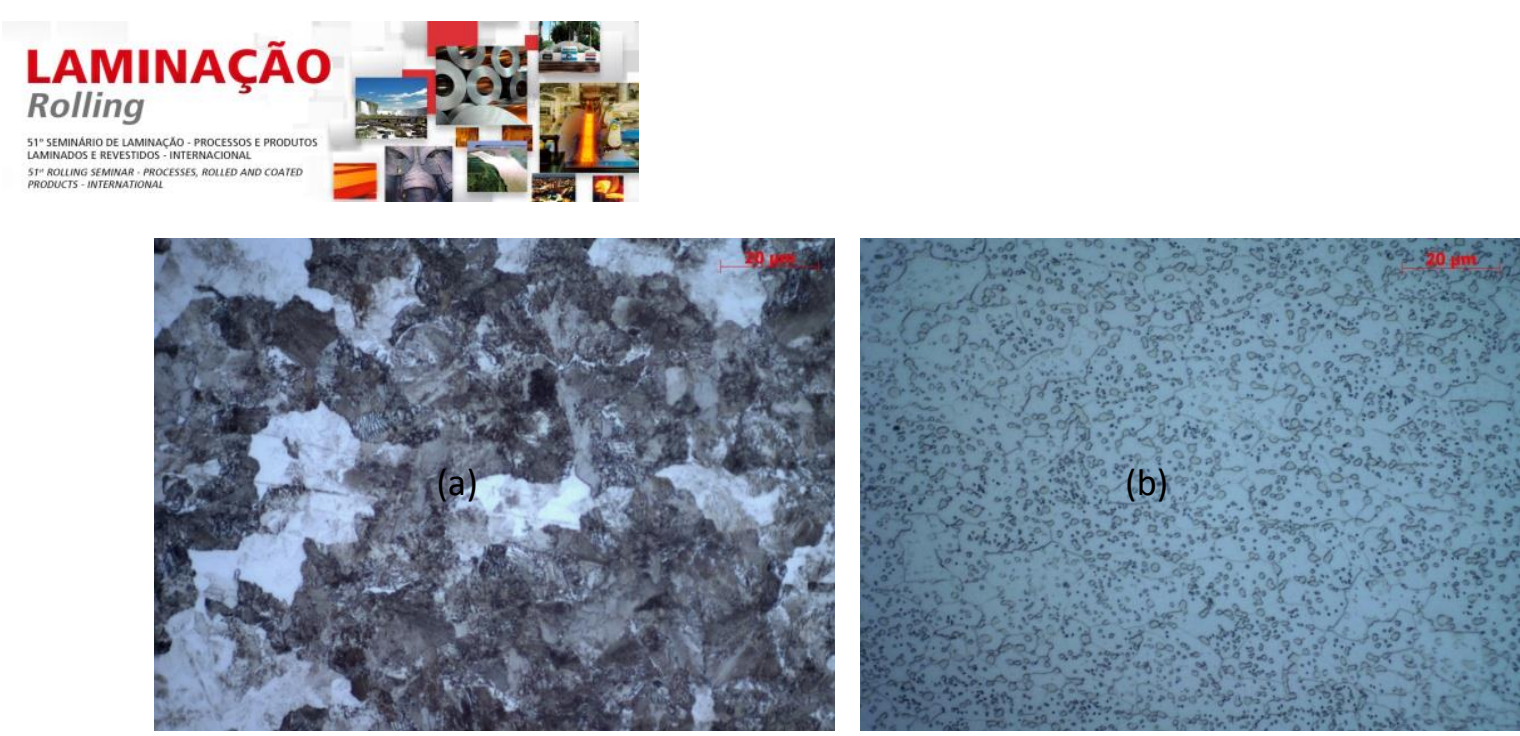

Figura 11: Microestruturas do material laminado a quente (a) e relaminado e esferoidizado (b). Aumento de $1000 \times$ com ataque Nital $3 \%$.

\subsection{Nível de Inclusões (MO)}

Análise adicional foi realizada para classificação do nível de inclusão conforme norma NM88:2000 onde constatou-se inclusão do tipo D (óxido globular), nível 1 e série fina (D1F) por análise comparativa conforme figura 12.

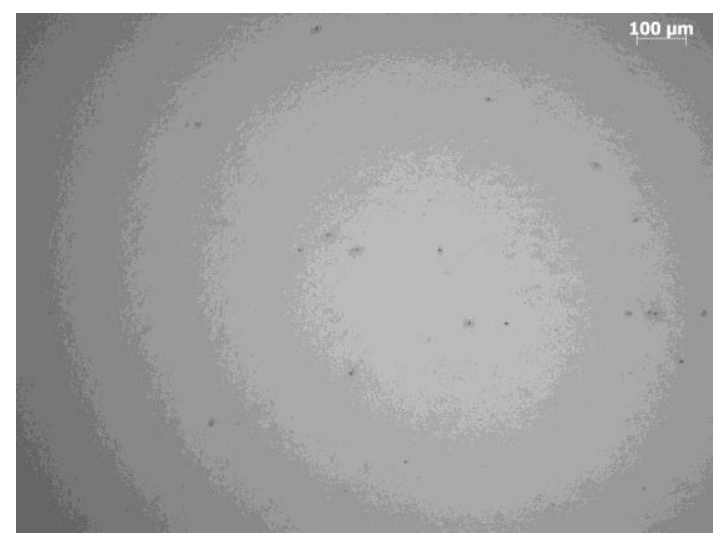

Figura 12: Nível de inclusão da amostra teste. Aumento 100x sem ataque

\subsection{CLC através do Ensaio Nakazima}

Com a metodologia descrita no item 2.5, dados de deformações principais foram coletados sendo possível realizar esboço da CLC para o material C80M esferoidizado com e sem revestimento de fosfato conforme segue nas figuras $13 \mathrm{e}$ 14:

* Contribuição técnica ao $51^{\circ}$ Seminário de Laminação - Processos e Produtos Laminados e Revestidos, 28 a 31 de outubro de 2014, Foz do Iguaçu, PR, Brasil. 

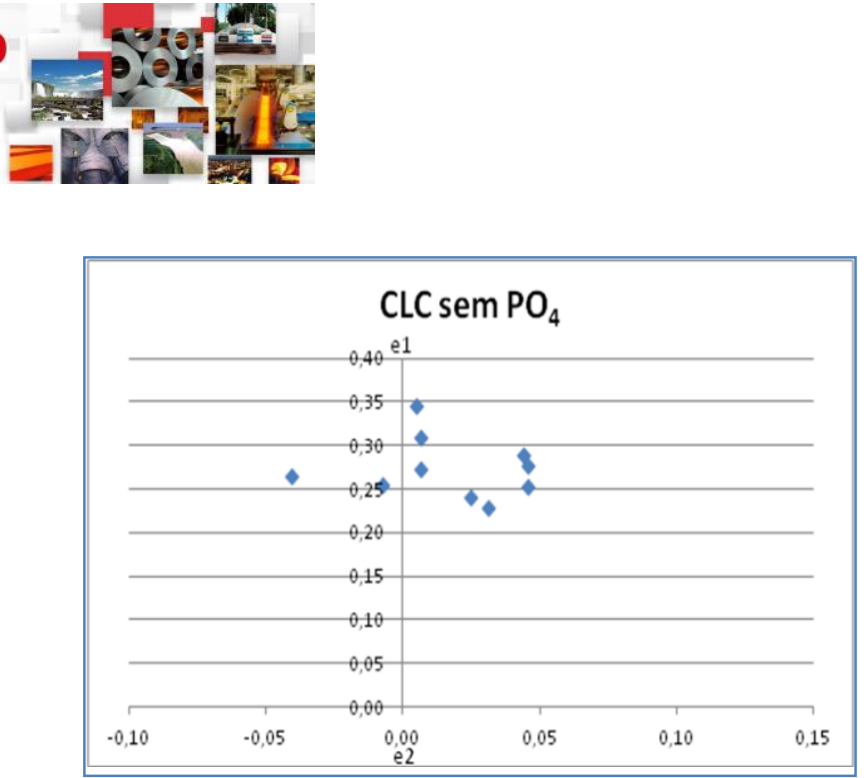

Figura 13: Pontos de deformações principais levantados com a conformação dos corpos de prova com revestimento de fosfato.

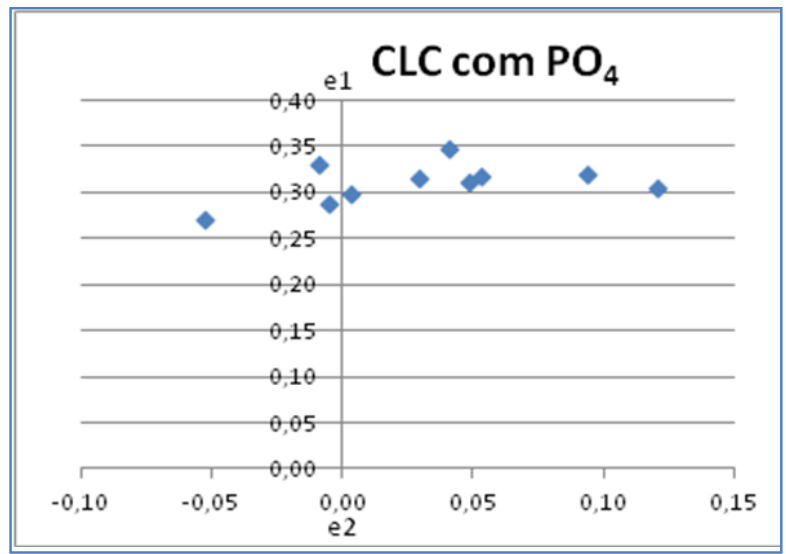

Figura 14: Pontos de deformações principais levantados com a conformação dos corpos de prova sem revestimento.

As amostras conformadas com larguras de 56 e $64 \mathrm{~mm}$, associadas ao lado de $\varepsilon_{2}$ negativo (tração-compressão) apresentaram ruptura na base e, por esse motivo, tiveram de ser descartadas do teste.

\subsection{Deslocamento do Punção}

Com os valores de deslocamento do punção coletados para a conformação das amostras sem e com o revestimento de fosfato, foi possível elaborar os gráficos, vistos nas figuras 15 e 16 :

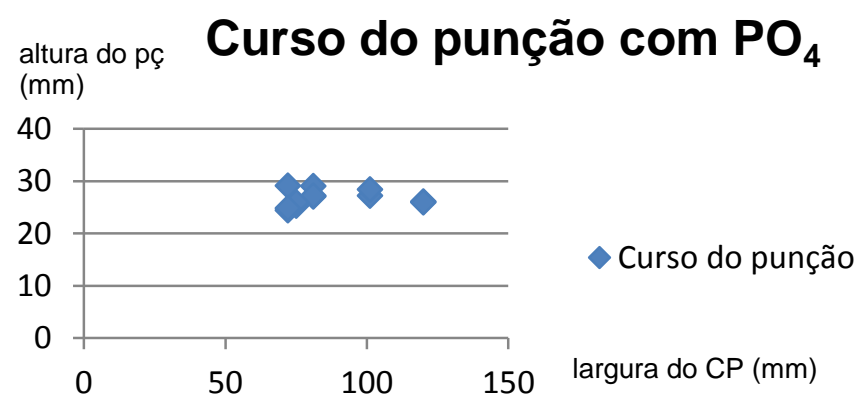

Figura 15: Curso do punção na conformação das amostras com revestimento de fosfato

\footnotetext{
* Contribuição técnica ao $51^{\circ}$ Seminário de Laminação - Processos e Produtos Laminados e Revestidos, 28 a 31 de outubro de 2014, Foz do Iguaçu, PR, Brasil.
} 

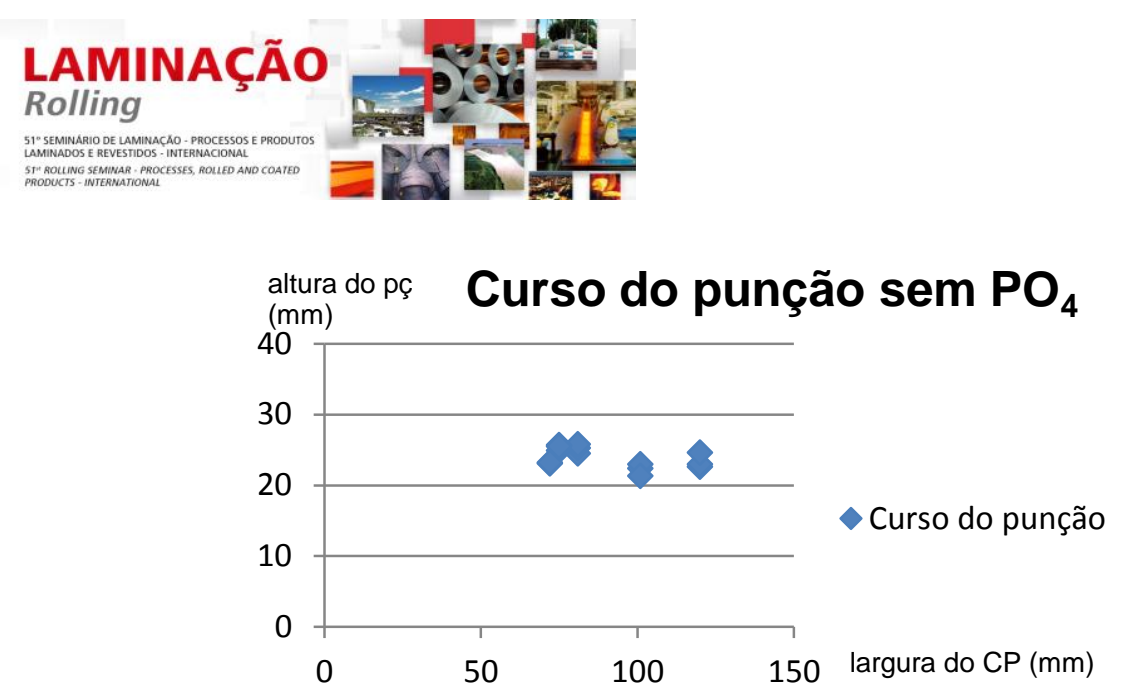

Figura 16: Curso do punção na conformação das amostras sem revestimento.

\subsection{Forças no Punção}

De acordo com a metodologia explicada no item 2.5, com os valores de força no punção coletados para a conformação das amostras sem e com revestimento de fosfato, foi possível elaborar os gráficos, vistos nas figuras 17 e 18:

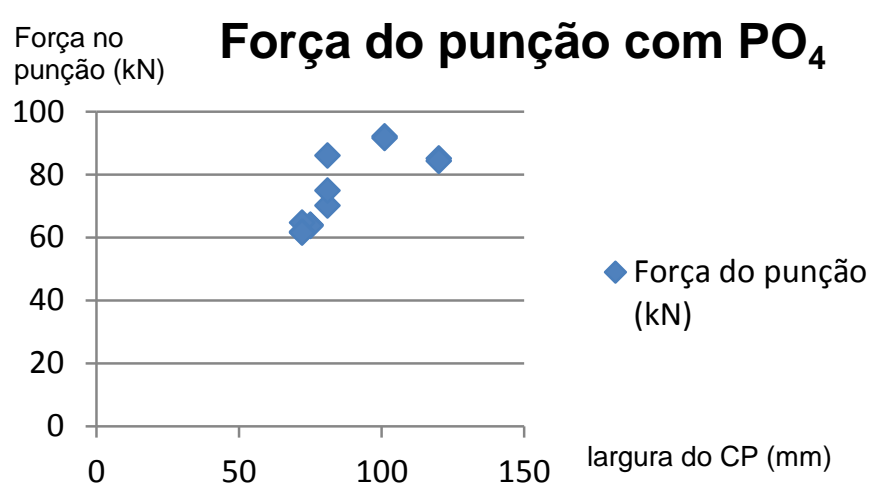

Figura 17: Medidas de força no punção para amostras conformadas com revestimento de fosfato.

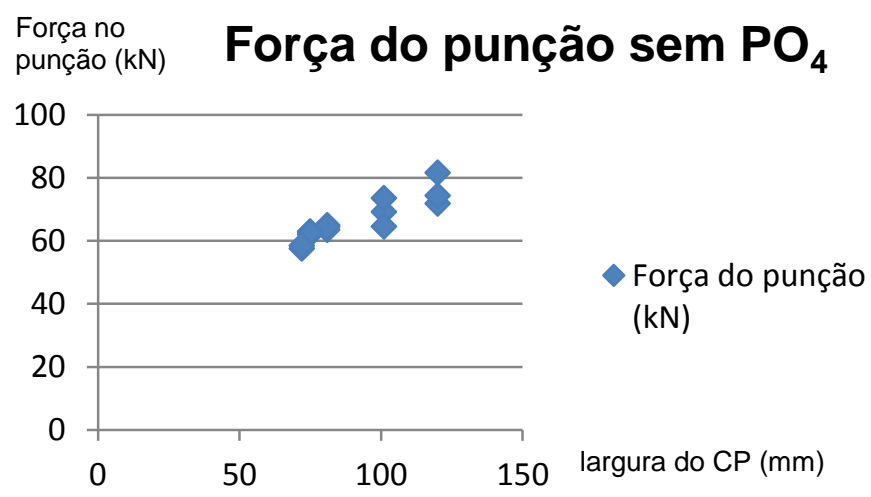

Figura 18: Medidas de força no punção para amostras conformadas sem revestimento.

\section{DISCUSSÃo}

\subsection{Microestrutura}

Foi possível constatar a evolução microestrutural com o processo empregado onde, partindo-se de um material laminado a quente com estrutura lamelar, atingiu-se esferoidização 100\% conforme análise comparativa da norma SEP 1520, tal

* Contribuição técnica ao $51^{\circ}$ Seminário de Laminação - Processos e Produtos Laminados e Revestidos, 28 a 31 de outubro de 2014, Foz do Iguaçu, PR, Brasil. 


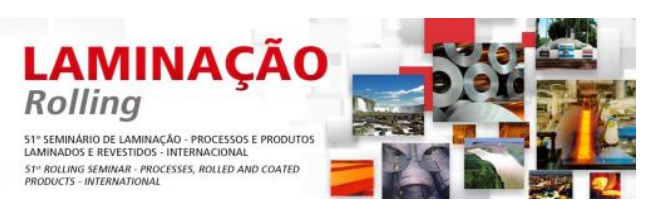

estrutura promove a redução das propriedades mecânicas facilitando a estampagem do material e minimizando a incidência de trincas durante a conformação da peça. $O$ resultado encontrado está de acordo com o verificado por Fagundes [12].

\subsection{Deslocamento/Força no Punção}

Comparando-se os resultados de deslocamento do punção até o início da estricção, foi possível constatar um deslocamento sistematicamente maior no material com revestimento de fosfato comparando-se com o material não revestido, isso deve-se a redução no atrito promovido pela camada de fosfato. Este fato corrobora as observações feitas por Narayanan [11] e llayiavel [10] consagrando o fosfato como excelente lubrificante e redutor de atrito durante processos de conformação.

Com os resultados encontrados de força máxima no punção até início da estricção, pode-se verificar uma força sistematicamente maior no material revestido se for comparado com a força verificada no material não revestido. Acredita-se que estes resultados sejam devido a maior deformação na amostra revestida promovendo maior encruamento e, por consequência, maior elevação de sua dureza, uma vez que o deslocamento no punção até a ruptura da amostra foi maior.

\subsection{Levantamento da CLC}

Foi possível verificar pontos da CLC para as amostras de material C80 modificado com e sem o revestimento de fosfato, entretanto devido a dificuldades na conformação de amostras mais estreitas (larguras abaixo de $72 \mathrm{~mm}$ ), verificou-se a maioria dos pontos válidos do lado de estiramento da curva (lado tração-tração), pois do lado de estampagem profunda (lado tração-compressão) as amostras apresentaram estricção em sua base e não no topo do domo, invalidando os resultados de deformações principais. Com os resultados encontrados do lado de estiramento da curva foi possível constatar uma elevação na curva CLC quando da conformação da amostra revestida, se comparada com a curva CLC da amostra não revestida. Os resultados encontrados estão de acordo com a literatura verificada, uma vez que Graf \& Hosford [15] constataram que, com a ausência de lubrificante, o caminho de deformação tende a se deslocar em direção do eixo $\varepsilon_{1}$, região de deformação planar, reduzindo dessa forma a posição da CLC.

\section{CONCLUSÕES}

Através dos testes conduzidos foi possível concluir:

- A presença de revestimento de fosfato com adição de sabão promove elevação da curva CLC;

- Houve aumento sistemático no deslocamento do punção ao final do processo de conformação da amostra fosfatizada se comparada com a conformação da amostra não revestida;

- Houve aumento sistemático na força do punção ao final do processo de conformação da amostra com revestimento de fosfato se comparada com a conformação da amostra não revestida;

- Com o processo de relaminação e esferoidização empregado foi possível obter esferoidização de $100 \%$ conforme figura 15 da norma DIN SEP 1520:1998.

\footnotetext{
* Contribuição técnica ao $51^{\circ}$ Seminário de Laminação - Processos e Produtos Laminados e Revestidos, 28 a 31 de outubro de 2014, Foz do Iguaçu, PR, Brasil.
} 


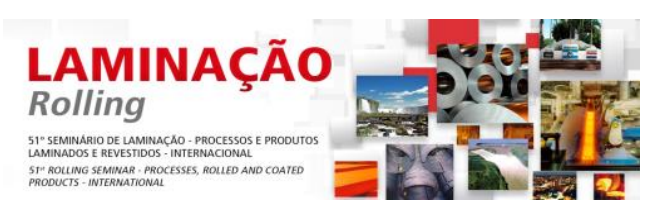

\section{Agradecimentos}

O autor agradece a empresa Brasmetal Waelzholz, em especial ao Sr. André Sereno por incentivar o desenvolvimento do projeto.

Agradecimento especial deve ser conferido ao Professor Doutor Ronald Lesley Plaut que orientou o projeto e o Professor Valdir Costa (Faculdade de Tecnologia da Termomecânica) que cedeu gentilmente 0 equipamento Erichsen para as conformações pelo teste Nakazima.

\section{REFERÊNCIAS}

1 Martins IA. Refino de Grão na transformação austenítica em aço rolamento previamente conformado a frio [dissertação de Mestrado]. São Paulo: UFScar; 2012.

2 Santos CAL, Farias MCM, Leite E, Filho AF, Panossian Z, Sinátora A. Comportamento de camadas fosfatizadas frente a corrosão e ao atrito. Intercorr; 2010.

3 Nakazima K, Kikuma T, Hasuka K. Study on the formability of steel sheets. Yawata Technical Report. 1968; p.111-141.

4 Reyman WP. Automotive Sheet Metal Stamping and Formability; 1990. pp.64-67

5 Keeler SP, Backofen WA. Plastic Instability and Fracture in Sheets Stretched Over Rigid Punches. ASM Trans. 1964;56(march):25-48

6 Keeler SP. Sheet Met. Ind. 1965;42:683.

7 Goodwin GM. Application of strain analysis to sheet metal forming problems in the press shop. SAE Paper no. 680093; 1968.

8 Holmberg S, Enquist B, Thilderkvist P. Evaluation of Sheet Metal Formability by Tensile Tests. Journal of Materials Processing Technology. 2004;145:72-83.

9 Marciniak Z, Kuczynski K. Limit strain in the processes of stretch-forming sheet metals. Int. J. Mech. Sci. 1967;9:609-620.

10 llayavel S, Venkatesan A. Study on phosphate conversion coating on wear resistance applications - a review. Journal of Engineering Research and Studies - JERS. 2010;1:14 .

11 Narayanan TS, Subbaiyan M. Acceleration of the Phosphating Process: An Overview. Prod. Finish. 1992; Sept:6-7.

12 Fagundes EJ. Análise da Influência do Ciclo de Recozimento de Esferoidização nas Propriedades Mecânicas do Aço SAE 1050 [dissertação de Mestrado]. Belo Horizonte: Universidade Federal de Minas Gerais; 2006. p.9-10.

13 Storojeva L, Ponge D, Kaspar R, Raabe D. Development of microstructure and texture of medium carbon steel during heavy warm deformation. Acta Materialia, Max-PlanckInstitut fur Eisenforschung, 2004.

14 Plaut RL. Estampabilidade de Chapas: Ensaios e Aplicações. In: II Workshop sobre Textura e Relações de Orientação; 2003. São Paulo: Instituto de Pesquisas Energéticas e Nucleares; 2003.

15 Hosford WF, Graf AF. Met.Trans. 1993;24a :2497-2501.

* Contribuição técnica ao $51^{\circ}$ Seminário de Laminação - Processos e Produtos Laminados e Revestidos, 28 a 31 de outubro de 2014, Foz do Iguaçu, PR, Brasil. 